\title{
A sismicidade no Curso de Sismologia (1970) de Frederico Machado e seis cartas históricas de isossistas com interesse para o Ensino de Ciências
}

\author{
Jorge Miguel Quintino Gomes Ferreira
}

\begin{abstract}
Resumo
Nos documentos curriculares portugueses em vigor para a disciplina de Ciências Naturais, $7 .^{\circ}$ ano de escolaridade, há uma orientação no sentido da exploração e discussão de cartas de isossistas relativas a sismos com efeitos no território nacional. Neste trabalho incluímos alguns apontamentos históricos sobre o conceito de intensidade sísmica, a qual permite a medição de um terramoto sem recurso a instrumentos, e apresentamos seis cartas de isossistas que constam no Curso de Sismologia (1970) de Frederico Machado. Para cada carta de isossistas analisámos as fontes utilizadas pelo autor e produzimos uma reflexão com sugestões para exploração em contexto didático. Verificámos que estas cartas são representativas da sismicidade no território português e constituem uma oportunidade para explorar o conceito de intensidade sísmica e corresponder às orientações curriculares (ensino básico) para este tema.
\end{abstract}

Palavras-chave: História da Sismologia, intensidade sísmica, cartas de isossistas

\begin{abstract}
In current portuguese curricular documents for the Natural Sciences subject, 7th grade, there is an orientation towards exploring and discussing isoseismal maps related to earthquakes with effects in the portuguese territory. In this work we include some historical notes about the concept of seismic intensity, which allows the measurement of an earthquake without the use of instruments, and we present six isoseismals maps that are included in Curso de Sismologia (1970) by Frederico Machado. For each isoseismal map we analyzed the sources used by the author and we produced a reflection with suggestions for didactic exploration. We found that these maps are representative of the seismicity in the Portuguese territory and provide an opportunity to explore the concept of seismic intensity and to meet the curricular orientations (basic education) for this theme.
\end{abstract}

Keywords: History of Seismology, seismic intensity, isoseismal maps

\section{INTRODUÇÃO}

Nos vários documentos curriculares em vigor relativos aos conteúdos para a disciplina de Ciências Naturais, $7 .^{\circ}$ ano de escolaridade, há uma orientação em comum no sentido da utilização de cartas de isossistas relativas a sismos com efeitos no território nacional. Uma importante fonte para corresponder às orientações curriculares, onde consta uma seleção de cartas de isossistas relativas a sismos históricos, caracterizando a sismicidade em Portugal, é o Curso de Sismologia de Frederico Machado. Cada uma destas cartas, baseada no conceito de intensidade sísmica, será aqui analisada de forma contextualizada, segundo as fontes utilizadas pelo autor, e com recomendações para exploração didática.

Em manuais escolares da disciplina de Ciências Naturais do $7 .^{\circ}$ ano de escolaridade foi possível observar que cada um integra pelo menos uma carta de isossistas e relativa ao contexto nacional ${ }^{1}$. As

\footnotetext{
${ }^{1}$ Ferreira, Uma reflexão sobre o ensino da ciência dos sismos, 85-96.
} 
cartas de isossistas apresentadas dizem respeito ao terramoto de Lisboa de 1755, ao sismo de Benavente de 1909, ao sismo do Faial de 1958 e ao sismo nos Açores de 1998. Também a carta portuguesa de isossistas, de intensidades máximas, constava na maioria dos manuais analisados. Mas o facto de em apenas um dos manuais a carta estar devidamente referenciada poderá indiciar alguma dificuldade dos autores dos manuais em conhecer e aceder a fontes originais, o que confere mais relevância ao objetivo do presente texto.

Numa perspetiva histórica, sabemos que as isossistas já foram utilizadas na sequência de um sismo com efeitos destrutivos ocorrido em dezembro de 1857, no sul de Itália, e nas décadas que se seguiram a intensidade sísmica foi a medida mais utilizada para avaliar a "dimensão" de um sismo². Porém, o desenvolvimento da instrumentação sismográfica dá origem a uma "nova sismologia" a partir de 1880, o que vai permitir que no século XX passe a existir uma outra abordagem para avaliar a "dimensão" do sismo, a magnitude. A "era moderna" chega já na década de 60 com a expansão do fundo dos oceanos e com a tectónica de placas a fornecerem uma explicação para a sismicidade 3 .

É no alvor deste novo paradigma que o faialense Frederico Machado (1918-2000) vai lecionar Sismologia na Faculdade de Ciências de Lisboa, no segundo semestre de 1966. As lições foram usadas por este engenheiro civil, que se vinha notabilizando no domínio da Geofísica e que tinha tido ação direta na evacuação de populações após uma série sísmica ocorrida por ocasião da erupção dos Capelinhos, para organizar o texto do Curso de Sismologia. Esta publicação editada em 1970 pela Junta de Investigações do Ultramar destinava-se "fundamentalmente" aos alunos do curso de Geologia, mas incluindo seis capítulos dedicados aos aspetos físico-matemáticos. O Curso de Sismologia também inclui dois capítulos sobre sismicidade dos territórios portugueses, nos quais constam algumas cartas de isossistas relativas a sismos históricos. Como as isossistas baseiam-se na intensidade sísmica, apresentamos agora alguns apontamentos históricos sobre este conceito, para de seguida analisarmos cada uma dessas cartas de isossistas, com o objetivo de apresentar sugestões de exploração em contexto didático.

\section{A INTENSIDADE SÍSMICA COMO FORMA DE MEDIR UM TERRAMOTO}

Os dados sobre intensidade sísmica (os efeitos do sismo) podem ser apresentados na forma de carta ou mapa e os pontos assinalados com a mesma intensidade podem definir linhas chamadas isossistas. Por defeito, as isossistas tendem a ser concêntricas, embora quando se pretende maior rigor as linhas possam apresentar-se mais convolutas. Por razões diversas (e.g. condições do solo) há valores discordantes daqueles que correspondem a uma determinada área de intensidade. Estes desvios devem

\footnotetext{
2 Bolt, Earthquakes, 100.

${ }^{3}$ Agnew, History of Seismology, 10-11.
} 
ser ignorados quando se desenham as isossistas, pois é mais importante exibir a tendência geral dos dados para as condições médias do solo, o que implica alguma subjetividade quando se desenham isossistas 4 .

Em termos históricos, a avaliação da intensidade foi importante porque permitiu a medição de um terramoto sem recurso a instrumentos. A avaliação da intensidade com base nos efeitos percetíveis dos terramotos, ou seja, sem recurso a instrumentos, generalizou-se nas últimas décadas do século XIX, através da escala Rossi-Forel (1883) de dez graus, a primeira escala a ser usada internacionalmente. A escala de Sieberg $(1912,1923)$ já é uma escala de doze graus, cuja versão de 1923 é traduzida para inglês em 1931 e verificada por Richter em 1956, originando a Escala Modificada de Mercalli de 1956. Mais recente é a Escala Macrossísmica Europeia 1998 que inclui linhas orientadoras, para reduzir a subjetividade na sua aplicação ${ }^{5}$.

O estudo dos efeitos do terramoto de 1755 teve uma primeira abordagem moderna, promovida pelo Marquês de Pombal, através de um questionário distribuído por todas as paróquias do Reino, mas este levantamento terá sido realizado mais para o propósito da reconstrução6 (Oldroyd, 2007). Após o já referido terramoto ocorrido no sul da Itália, em dezembro de 1857, Robert Mallet (1810-1881) concretizou o que se pode considerar um estudo científico sobre a intensidade de um sismo, utilizando como métodos a cartografia e a catalogação detalhada dos relatos e danos sentidos nos edifícios e na superfície terrestre para medir a força e distribuição do movimento sísmico. Ao desenhar as linhas que uniam locais com 0 mesmo tipo de danos ou intensidade (que designou por isossísmicas), o padrão das linhas isossistas permitia a Mallet determinar a fonte das ondas sísmicas e conhecer a taxa a que os efeitos do abalo diminuíam com a distância, proporcionando uma estimativa da dimensão relativa do terramoto7.

O estudo da intensidade passou depois a ser feito com recurso a questionários que eram respondidos por pessoas da área afetada. As respostas permitiam elaborar um mapa em que as áreas de igual intensidade ficavam limitadas das outras através de um contorno (a isossista). Este mapa proporcionava não só informação sobre a distribuição do abalo a partir da fonte mas, quando comparado com um mapa geológico, era possível investigar sobre o efeito resultante do tipo de rocha/solo na intensidade. Na sequência do terramoto de São Francisco, em 1906, a utilização deste método permitiu demonstrar a existência de uma relação entre o tipo de rocha e a distribuição da intensidade do terramoto 8

\footnotetext{
${ }^{4}$ Musson \& Cecic, Macroseismology, 811.

5 Musson et al. The comparison of macroseismic intensity scales, 426.

6 Oldroyd et al. The study of earthquakes, 363.

7 Bolt, Earthquakes, 99.

8 Bolt, Earthquakes, 102.
} 
Ao contrário do que acontece com a intensidade, a magnitude é uma medida que não depende nem da densidade populacional nem do tipo de construção, mas antes da amplitude das ondas sísmicas, registadas nos sismogramas. A sismologia instrumental trouxe a oportunidade de comparar sismos a nível mundial, quer eles se fizessem sentir em regiões habitadas, quer não. À medida que a capacidade da monitorização instrumental foi melhorando, ao longo do século $X X$, verificou-se um desinteresse na investigação sem sismógrafos (macrossísmica) e na medição da intensidade dos terramotos. Porém, a partir do meio da década de 70, voltou a haver interesse por este assunto, tendo em vista a avaliação do risco sísmico. A macrossismologia tinha a vantagem de poder ser aplicada a acontecimentos sísmicos que ocorreram antes de estarem disponíveis instrumentos de medição ou em locais não abrangidos por esses instrumentos. Bastava que a região fosse povoada e que os seus habitantes tivessem deixado algum tipo de registo sobre os terramotos que sentiram ${ }^{9}$.

A correlação entre a abordagem macrossísmica e a abordagem instrumental é uma preocupação que se regista no Curso de Sismologia. A escala de intensidades em que Frederico Machado se baseia para apresentar as cartas de isossistas é a de Mercalli de 1931 (doze graus), apresentando uma forma abreviada $^{10}$ e referindo ter sido adotada por José Agostinho e usada nos Açores. A propósito desta escala, Frederico Machado refere ter caráter "estatístico"11 e que foi estabelecida para ter correlação com a aceleração máxima do solo obtida a partir de sismogramas.

Uma distribuição teórica das intensidades (que numa crusta homogénea seriam circunferências concêntricas, em torno do epicentro) pode ser estabelecida, refere Frederico Machado, desde que se conheçam as acelerações a duas distâncias do epicentro e aplicando uma equação para determinar a profundidade do foco. A já referida abordagem física e matemática que caracteriza este Curso de Sismologia está novamente patente nas equações que apresenta e que permitem relacionar a intensidade e a aceleração máxima. Os desvios das intensidades reais relativamente às teóricas remetem para "anomalias" que Frederico Machado refere terem "considerável interesse geológico"12.

A determinação da profundidade do foco a partir de dados macrossísmicos já tinha sido desenvolvida por Radó Kövesligethy (1862-1934), considerando a intensidade epicentral e a intensidade de uma determinada isossista. Mais do que intensidade epicentral, que pode ser afetada pela profundidade do foco, a área total onde o terramoto foi percebido (ou a área abrangida por uma das isossistas mais afastada, como a 3 ou a 4) pode, após aplicação de mais uma equação, constituir um bom

\footnotetext{
9 Musson \& Cecic, Macroseismology, 807-821.

10 Machado, Curso de Sismologia, 113-114.

11 Machado, Curso de Sismologia, 115.

12 Machado, Curso de Sismologia, 116.
} 
indicador da magnitude ${ }^{13}$. Os dados macrossísmicos passaram assim a fornecer valores consistentes de magnitude, o que é relevante para estudos de sismicidade histórica e, por conseguinte, de risco sísmico.

\section{A SISMICIDADE DE UMA REGIÃO}

A intensidade e a frequência dos sismos e o número de epicentros são elementos que permitem avaliar a atividade sísmica (sismicidade) de uma região. Com base numa lista de macrossismos sentidos em Portugal no período de 1901 a 1954, Alfredo Mendes, meteorologista do Serviço Meteorológico Nacional, no simpósio sobre a ação de sismos e sua consideração no cálculo das construções, realizado em novembro de 1955, conclui que o território português com maior atividade sísmica (que na altura incluía o território do ultramar) era o arquipélago dos Açores, destacando-se neste arquipélago, por uma maior frequência de sismos (41\%), a ilha do Faial. Um cálculo da sismicidade tendo em atenção o número de sismos, pela área considerada e o número de anos de observações, permitia reconhecer o distrito de Lisboa como o de maior sismicidade no continente ${ }^{14}$.

Numa perspetiva enquadrada com a valorização da sismologia instrumental e dos dados sismográficos, Frederico Machado (que também participou no referido simpósio sobre a ação de sismos) refere no Curso de Sismologia que a avaliação da intensidade é "um pouco subjectiva"15, pelo que prefere calcular a energia libertada que poderá caracterizar a sismicidade de uma região a partir da magnitude, ou seja, a partir de sismogramas. Seguindo uma abordagem fisico-matemática, usando equações que se convertem noutras equações, Frederico Machado também apresenta uma fórmula que relaciona a energia libertada (ou magnitude) e a intensidade epicentral, salientando que se conhecer a energia de todos os abalos de uma dada região, a sismicidade poderá ser caracterizada com "mais rigor"16. Mas conclui que a "existência ou não de abalos destruidores" é o critério que, na prática, define a sismicidade de uma região.

A propósito da distribuição geográfica dos sismos, Frederico Machado refere que as áreas sísmicas "coincidem com os grandes enrugamentos cenozoicos"17. A área sísmica do Mediterrâneo ocidental, prolongando-se da cintura alpina até aos Açores (que hoje sabemos constituir um limite de placas), será relevante para Portugal, pelo que o autor do Curso de Sismologia descreve exemplos ocorridos nesta área, três fora do território português (Messina, 1908; Orleansville, 1954; Agadir, 1960), três no território português continental (Lisboa, 1755; Benavente, 1909; Atlântico, 1941) e três no território português insular dos Açores (S. Miguel, 1522; S. Jorge, 1757; Faial, 1926). Apesar de todos estes exemplos serem acompanhados de cartas de isossistas, iremos refletir apenas sobre aquelas que dizem

\footnotetext{
13 Musson \& Cecic, Macroseismology, 811-812.

14 Mendes, Contribuição para o conhecimento da sismicidade, 1-4.

15 Machado, Curso de Sismologia, 118.

16 Machado, Curso de Sismologia, 119.

17 Machado, Curso de Sismologia, 125.
} 
respeito ao território nacional, uma escolha orientada para corresponder ao que é preconizado nos documentos curriculares $\left(7 .^{\circ}\right.$ ano de escolaridade).

\section{1-A carta de isossistas relativa ao terramoto de Lisboa de 1755}

Frederico Machado anuncia este terramoto como o de maior magnitude a nível mundial, com intensidade de 9 a 10 em Lisboa, no Algarve e em Marrocos. A respetiva carta de isossistas, que integra 0 Curso de Sismologia, já havia sido publicada em 1966, na revista da Faculdade de Ciências, num texto com a designação "Contribuição para o estudo do Terramoto de 1 de novembro de 1755"18. Neste texto, a distribuição das intensidades, informa o autor, foi possível a partir de estudos de Moreira de Mendonça (1758), de Pereira de Sousa (1919-1932), de Woerle (1900) e de Reid (1914).

Com base nos dados dos estudos referidos, Frederico Machado atribuía um valor médio de 9 para Lisboa, uma vez estarem assinaladas intensidades que variam de 8 a 10. Seguindo o mesmo critério, atribui o valor de 9,5 a Setúbal e conclui que a intensidade terá sido máxima em Meknes, Marrocos, onde se atingiu o grau 10 e admite mesmo que a isossista 10,5 terá penetrado neste território africano. Ao interpretar as isossistas, Frederico Machado refere que o alongamento das curvas é compatível com a hipótese de um sistema de pelo menos duas falhas, uma com orientação E-W, prolongando-se entre Marrocos e os Açores, a outra com orientação SW-NE, mais curta e eventualmente responsável pelos abalos com epicentro no vale do Tejo ou no do Sado. Portanto, no terramoto de 1755, poderá ter havido deslizamento em ambas as falhas.

O parâmetro magnitude não foi possível ser determinado em 1755, pois o terramoto ocorreu, como é sabido, num período ainda pré-instrumental. No entanto, com uma abordagem físico-matemática, foi possível relacionar a magnitude com a intensidade epicentral, que Frederico Machado admite ter sido 12. Com este valor obteve uma magnitude de 9 , um valor superior ao de qualquer terramoto registado até então e que Frederico Machado considera compatível com a grande área de percetibilidade e com fenómenos secundários ocorridos fora desta área, como as oscilações em lagos.

Numa perspetiva de ensino, a carta de isossistas sobre o terramoto de 1755 que consta no Curso de Sismologia permite conhecer a localização de um foco sísmico que será responsável pelos terramotos com mais efeitos destruidores no território continental de Portugal, conhecer o caráter extraordinário da enorme área de percetibilidade do terramoto de 1755 , e relacionar um sistema de falhas com a distorção/anomalias das isossistas. Tendo em atenção que o sismo ocorreu num período préinstrumental, mostra-se que o estudo de uma ocorrência sísmica é possível sem instrumentos e que a abundância de relatos que surgiram na sequência do acontecimento sísmico de 1755 contribuiu para que

18 Machado, Contribuição para o estudo do Terramoto, 19-31. 
autores como Pereira de Sousa, no início do século XX, e Frederico Machado, já na segunda metade do século XX, estudassem este terramoto, usando um conceito, a intensidade sísmica, o qual permite a comparação com outros terramotos que já puderam ser registados por instrumentação sismográfica.

\section{2-A carta de isossistas relativa ao terramoto de Benavente de 1909}

Este sismo é apresentado por Frederico Machado como um dos mais fortes que se pode esperar em Portugal com epicentro em terra. A provável causa do terramoto de Benavente é atribuída a uma diretriz tectónica com direção SW-NE e com penetração nos vales do Sado e do Tejo. A energia libertada na origem, referida então a $30 \mathrm{~km}$ de profundidade, originou um sismo com magnitude 6,7 e um raio de percetibilidade de $450 \mathrm{~km}$. Com base em elementos de Choffat e Bensaúde (1912), Frederico Machado apresenta uma carta de isossistas, na qual podemos verificar que a intensidade no epicentro, com localização terrestre, terá sido inferior a 9.

O estudo oficial, de Paul Choffat e Alfredo Bensaúde (1912), e o de iniciativa individual com recurso a informação sismográfica obtida em Coimbra, por Ferreira Diniz (1911), podem ser considerados estudos coevos, e numa época em que a sismologia instrumental nacional ensaiava os primeiros passos. Este terramoto foi posteriormente alvo de diversos estudos que foram diminuindo a "força" que the foi atribuída inicialmente, uma avaliação baseada em registos instrumentais e em maior número de registos. Mesmo assim, terá sido um dos sismos com maior efeito destruidor em território continental nacional e com repercussão significativa ao nível do desenvolvimento da sismologia em Portugal.

Um desses estudos posterior foi elaborado por um grupo de autores nacionais e internacionais, compilando 32 sismogramas de 14 estações sísmicas europeias (não incluindo o da estação sismográfica de Coimbra) e confirmando um valor de magnitude de 6,13 (e de 6,35 para as ondas superficiais). Quanto à localização epicentral, embora os dados disponíveis não permitam uma determinação com qualidade, os autores deste estado da arte sobre o terramoto de Benavente concluem ser possível que a falha da Azambuja, uma falha potencialmente ativa que existe na região do Vale Inferior do Tejo, tenha sido responsável pela geração do sismo, e com uma profundidade do foco situada entre 2 e $16 \mathrm{~km}^{19}$.

Apesar dos focos dos sismos que poderão ter efeitos mais destruidores tenderem a localizar-se no mar, como sabemos, a SW do cabo de S. Vicente, a carta de isossistas do terramoto de Benavente, numa perspetiva didática, permitirá fornecer um exemplo de um sismo com epicentro em terra com efeitos igualmente destruidores. E os alunos poderão ser desafiados a refletir sobre o estado de conservação dos edifícios em 1909 e como a sua vulnerabilidade poderá ter contribuído para sobrestimar a avaliação da intensidade (influenciando os próprios dados da carta de isossistas) e introduzir subjetividade em parâmetros calculados com base nesses valores de intensidade.

\footnotetext{
19 Teves-Costa et al, O sismo de Benavente, 44-49.
} 
3.3-Terramoto de 25 de novembro de 1941, no Atlântico

Este sismo "notável" e de "extrema violência"20 teve epicentro no oceano, algures entre Portugal e os Açores, o que não impediu intensidades de 3 a 6 no território continental e insular, incluindo Madeira, mas suficientemente afastado para evitar efeitos associados a intensidades de grau superior. Na respetiva carta é possível observar que todas as isossistas de grau superior ou igual a seis limitam áreas que correspondem à superfície do oceano (e, por isso, a tracejado). Frederico Machado refere que as isossistas deste terramoto são baseadas em elementos de Vítor Moreira, que sabemos ter sido meteorologista do Serviço Meteorológico Nacional e autor de catálogos sobre a sismicidade histórica de Portugal continental $(1979,1984)$.

Este meteorologista também apresentou uma comunicação no Simpósio sobre a ação de sismos e sua consideração no cálculo das construções (1955),na qual encontramos uma carta do sismo de 1941 com as isossistas representadas apenas para o território continental português (isossistas de intensidade III a V), mas na respetiva descrição o autor da comunicação salienta tratar-se de "um dos sismos mais fortes com epicentro nesta zona". A distância do epicentro à costa portuguesa evitou consequências mais graves, referia Vítor Moreira, mas quebraram-se dois cabos submarinos e, em Lisboa, caíram chaminés, entre outros efeitos que abrangeram uma área de percetibilidade superior a $1000 \mathrm{~km}$, incluindo o norte do território nacional e Marrocos.

A partir de uma lista de 31 sismos ocorridos entre 1915 e 1954, com epicentros conhecidos e localizados no mar, Vítor Moreira identifica uma área não muito larga, que vai de Gibraltar aos Açores²1, onde os sismos tendem a não ser muito frequentes mas alguns registam magnitude elevada. $A$ faixa inclui o epicentro provável do sismo de 1 de novembro de 1755 e também o de 25 de novembro de 1941, 0 primeiro com 8,8 a 9 de magnitude estimada, o segundo 8,2 (respetivamente 9 e 8,3 segundo Frederico Machado).

Em contexto didático, a carta de isossistas deste sismo de 25 de novembro de 1941 pode servir como exemplo de mais um sismo de magnitude elevada com epicentro nesta importante área sísmica que hoje sabemos corresponder a um limite de placas, nem sempre com efeitos catastróficos dada a distância ao continente, e uma vez que é possível associar os epicentros de sismos históricos a falhas tectónicas, exemplifica-se como o estudo dos sismos pode contribuir para o conhecimento da constituição do fundo do oceano.

3.4-Sismo de S. Miguel, 22 de outubro de 1522

\footnotetext{
20 Machado, Curso de Sismologia, 138.

21 Moreira, Os territórios portugueses do Atlântico-Norte e as zonas sísmicas do Globo, 1-5.
} 
O primeiro dos três "maiores" terramotos, considera Frederico Machado, ocorridos nos Açores (após o povoamento), terá acontecido de madrugada, com epicentro na costa, junto a Vila Franca do Campo, onde terão morrido muitos habitantes na sequência de deslocamentos de terras.

Uma fonte especificamente dedicada ao estudo deste sismo consultada por Frederico Machado foi um texto do meteorologista António Alcântara de Mendonça Dias (1945), publicado na Insulana, o qual se baseia em referências de Gaspar Frutuoso, em Saudades da Terra. Mendonça Dias conclui que o abalo não esteve relacionado com qualquer manifestação vulcânica, tendo a sua origem num processo tectónico. O ruído sentido pouco antes do abalo mais violento prova que houve prévio escorregamento de massas no interior da crusta (ao longo de fraturas). Vila Franca do Campo terá ficado soterrada por um escorregamento de terra. Da notícia de Frutuoso foi possível avaliar a intensidade, que em Vila Franca terá sido de grau 10, e até mesmo esboçar uma carta de isossistas "para melhor entendimento do texto"22. Mendonça Dias refere ser tarefa difícil a determinação do epicentro a partir dos dados de Frutuoso, mas arrisca a região de Vila Franca, prolongando-se um pouco para o interior da ilha.

Cerca de 20 anos depois, também Frederico Machado escreve sobre este terramoto de 1522, com foco nas anomalias das intensidades. $\mathrm{O}$ autor determinou uma distribuição teórica das intensidades sísmicas e ao comparar esta distribuição com as intensidades observadas encontrou anomalias que considerou compatíveis com a existência de uma câmara magmática pouco profunda sob o vulcão da Água de Pau. O texto é acompanhado de quatro figuras, a primeira uma carta de isossistas prováveis semelhante à que consta no Curso de Sismologia (mas para além das isossistas com a indicação de intensidades em determinadas localidades), a segunda uma carta de linhas de igual anomalia e a terceira e quarta figuras são esquemas representando a provável localização da câmara magmática do vulcão da Água de Pau. Frederico Machado lembra que este vulcão viria a ter atividade eruptiva em 1563 e também em 1652.

As isossistas revelam assim um possível efeito de "sombra"23 devido à câmara magmática do vulcão de Água de Pau. Numa perspetiva didática, os alunos poderão ser desafiados a refletir, a partir da carta de isossistas do terramoto de 1522, em S. Miguel, sobre o porquê das isossistas não serem circunferências concêntricas, de modo a concluir que a existência de câmaras magmáticas nesta região sísmica, mas que também é vulcânica, poderá ser a razão para a atenuação dos efeitos das ondas sísmicas à superfície.

3.5-Terramoto de S. Jorge, de 1757

\footnotetext{
22 Dias, O sismo de 1522, 500.

23 Machado, Anomalias das intensidades do terramoto de S. Miguel, 109.
} 
Os efeitos deste terramoto incluíram a "quase total"24 ruína dos edifícios situados na parte leste da ilha, onde se terá atingido uma intensidade máxima de grau 11. Um quinto da população terá perdido a vida. Este terramoto, a que se seguiram algumas réplicas, é classificado como o mais violento dos Açores por Frederico Machado, que já em 1949, na revista Açoreana, escrevera sobre este acontecimento sísmico. Partindo de notícias coevas, ou seja, de relatos de quem testemunhou o acontecimento, avalia as intensidades sísmicas (segundo a Escala de Mercalli, 1931) e apresenta mesmo as isossistas numa carta, as quais estão representadas como circunferências concêntricas.

Ainda neste texto da Açoreana, e com base em equações, Frederico Machado determina a profundidade do foco $(10,7 \mathrm{~km})$ e refere não parecer haver ligação com qualquer manifestação vulcânica, pois se tal acontecesse a profundidade deveria ser inferior. Com este valor, determina a energia total (5x1024 ergs) e o raio teórico de percetibilidade $(422 \mathrm{~km})$, concluindo que estes parâmetros permitem classificar este terramoto como um dos grandes sismos mundiais. Para determinar 0 raio de percetibilidade (que faz corresponder ao raio da isossista 11/2, ou seja, à intensidade 1,5), Frederico Machado teve primeiro de determinar o raio teórico das diferentes isossistas, que aparecem na respetiva carta como circunferências concêntricas. Mas Frederico Machado alerta que, na prática, as curvas são irregulares, devido à "influência das variações petrológicas locais"25.

No Curso de Sismologia, Frederico Machado terá tido em atenção esta influência da natureza do subsolo nos efeitos à superfície das ondas sísmicas, pois as isossistas da carta que apresenta já não são circunferências completamente concêntricas. A falta de regularidade é evidente, por exemplo, nas isossistas que estão representadas na parte oeste da ilha de S. Jorge, atribuindo Frederico Machado a responsabilidade por esta irregularidade à presença das câmaras magmáticas de S. Jorge e do Pico. Também o valor de energia está atualizado para 3×1022 ergs, correspondendo a uma magnitude de 7,4. Esta carta de isossistas constitui mais uma fonte para que, numa perspetiva didática, se possa desafiar os alunos a refletir sobre a influência da natureza do subsolo e o caráter subjetivo da intensidade enquanto medida da grandeza de um sismo.

3.6-Carta de isossistas do terramoto do Faial, 31 de agosto de 1926

O epicentro deste terramoto localizou-se junto à cidade da Horta, onde se verificou muita ruína e a morte de nove pessoas. A intensidade epicentral foi de nove, mas já antes um abalo premonitório tinha atingido a intensidade 7. Estes dois abalos tiveram magnitudes semelhantes (o premonitório 6,2 e 0 principal 6,3), mas as profundidades do foco foram diferentes (o premonitório $50 \mathrm{~km}$ e o principal $13 \mathrm{~km}$ ), 0

\footnotetext{
24 Machado, Curso de Sismologia, 143.

25 Machado, O terramoto de S. Jorge em 1757, 321.
} 
que justificará uma maior intensidade do abalo principal. A carta de isossistas deste abalo está referenciada por Frederico Machado como sendo baseada em elementos de José Agostinho.

$\mathrm{Na}$ sequência da morte de Afonso Chaves, com quem iniciara uma estreita relação com a Meteorologia e com a Geofísica, José Agostinho (1888-1978) viria a substituí-lo como Diretor do Serviço Meteorológico dos Açores, no mesmo ano do terramoto, em 1926. E o estudo que faz deste terramoto leva-o a concluir ser o "maior" sentido no Faial desde o seu povoamento, mas não o que provocou mais danos nos Açores ${ }^{26}$. Apresenta duas cartas de isossistas, uma de todo o arquipélago, outra apenas da zona central. Com os raios das isossistas (que verificamos serem linhas concêntricas) determina a profundidade do foco segundo duas abordagens, obtendo de 1,6 a 4,8 km numa, e 1,2 km noutra, pelo que conclui que a origem foi superficial.

Num outro estudo que Frederico Machado consultou, José Agostinho (1935) referia ser evidente a relação entre atividade sísmica e vulcânica nos Açores, embora muitos sismos tenham uma origem tectónica e classificava mesmo o sismo de 31 de agosto de 1926 como um "abalo tectónico típico"27. 0 abalo de 1926, segundo José Agostinho, produziu danos insignificantes na parte das ilhas (Faial e Pico) onde há sinais de atividade vulcânica mais recente e danos maiores na parte mais antiga, como na Horta. E considera mesmo que "não são de esperar"28 abalos destruidores nas regiões com sinais mais recentes de atividade vulcânica.

Provavelmente tendo em conta esta informação, Frederico Machado considera que as áreas de maior redução da intensidade, na carta isossistas que integra o Curso de Sismologia, correspondem a duas "sombras" nítidas que atribui à presença de câmaras magmáticas (dos vulcões do Faial e do Pico). A carta que consta no Curso de Sismologia tem assim as isossistas traçadas de forma diferente da de José Agostinho. As que representam a intensidade na ilha do Faial e na ilha do Pico têm a concavidade para o lado oposto do epicentro, localizado algures entre as duas ilhas (e próximo da cidade da Horta, como já sabemos). Mais um exemplo para, em contexto didático, desafiar os alunos a interpretar uma redução heterogénea da intensidade em relação ao epicentro.

\section{NOTAS FINAIS}

As cartas de isossistas estão associadas, como vimos, a estudos sobre sismicidade, baseados no conceito de intensidade sísmica, que permitem determinar epicentros e avaliar o risco sísmico de uma região. Esta abordagem revela-se especialmente importante quando não é possível a abordagem instrumental (nos sismos ocorridos no período anterior à existência de instrumentos, como o de Lisboa,

\footnotetext{
${ }^{26}$ Agostinho, The earthquake in the Azores Islands, on 31st August 1926, 268-272.

27 Agostinho, Tectónica, sismicidade e vulcanismo das ilhas dos Açores, 91.

${ }^{28}$ Agostinho, Tectónica, sismicidade e vulcanismo das ilhas dos Açores, 92.
} 
em 1755). Nestes casos, tal como fazia Frederico Machado, pode utilizar-se uma abordagem físicomatemática para converter a informação macrossísmica nos parâmetros instrumentais, possibilitando a comparação de sismos ocorridos em diferentes épocas.

As cartas de isossistas que constam no Curso de Sismologia são representativas da sismicidade em território nacional, apresentando informação relevante e constituindo uma oportunidade para explorar 0 conceito de intensidade sísmica, portanto, adequadas para corresponder às orientações curriculares (ensino básico) para este tema. Ao consultar as fontes em que Frederico Machado se baseia, verificámos que as cartas de isossistas que constam no Curso de Sismologia, nalguns casos, são diferentes das cartas que constam nas fontes, levando a concluir que Frederico Machado, dispondo de mais informação, procurou tornar as cartas de isossistas mais atualizadas e mais rigorosas, e, por conseguinte, uma fonte ainda mais adequada para o ensino.

Os três terramotos ocorridos em Portugal Continental que constam no Curso de Sismologia de Frederico Machado na forma de carta de isossistas são exemplificativos de uma sismicidade histórica com origem na parte SW do território continental português e na falha do Vale Inferior do Tejo. Nos Açores, a frequência de sismos é muito elevada, com terramotos individualizados e também longas séries de sismos, mas com magnitude inferior à magnitude dos sismos com origem a SW do cabo de $\mathrm{S}$. Vicente, 0 que também é exemplificado pelas três cartas de isossistas que constam no Curso de Sismologia para este arquipélago. No caso dos Açores, a sismicidade está relacionada com a sua localização na junção tripla das Placas Euroasiática, Norte Americana e Africana.

A informação macrossísmica, relativa a todos os sismos sentidos numa dada zona, permite 0 traçado de cartas de isossistas de intensidades máximas, ou seja, o conhecimento em cada local da intensidade máxima observada, uma informação relevante na perspetiva da avaliação do risco sísmico e para estabelecer um regulamento de construção anti-sísmica adequado para cada região. Uma última sugestão em contexto didático é a utilização destas cartas de isossistas de intensidades máximas para que os alunos possam conhecer o maior grau de destruição historicamente ocorrido no local onde se insere a escola que frequentam, um conhecimento que pensamos poder contribuir para que os alunos em Portugal, que na sua maioria nunca sentiram um sismo, reconheçam o território nacional como uma região sísmica e fiquem motivados para o tema.

\section{SOBRE O AUTOR:}

Jorge Miguel Quintino Gomes Ferreira

Grupo de investigação IHC-CEHFCi da Universidade de Évora, Portugal

imggferreira68@gmail.com 